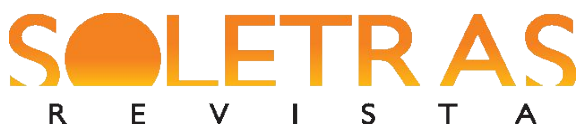

N. 38 - 2019.2 - ANA CLÁUDIA DE OLIVEIRA SILVA

\title{
A reescrita obsessiva da infância em dois livros de Salim Miguel: a criação de um "espaço autoficcional"
}

\author{
Ana Cláudia de Oliveira da Silva ${ }^{1}$
}

\begin{abstract}
RESUMO: Salim Miguel não escreve, ele reescreve. Seus textos consistem em uma reescrita obsessiva de fragmentos da própria infância que obstinadamente teimam em retornar para o sujeito adulto. São os mesmos pedaços de vida, mas sempre diferentes. Repetição de cenas literárias e personagens que permite pensar na construção de um "espaço autoficcional", local onde o escritor, atravessado pela experiência da diáspora, pode expressar-se livremente, mesmo que a imagem de si mesmo oferecida ao leitor seja múltipla, fragmentária e lacunar. É o que percebemos nos livros Onze de Biguaçu mais um (1997) e Reinvenção da infância (2011), objetos deste trabalho, os quais apresentam entre os percalços da infância e juventude, uma espécie de percurso de formação pessoal, moral e literária do filho mais velho do Seu Zé Miguel, personagem construída pelo autor para ficcionalizar a própria experiência. Com base nisso, objetivamos refletir sobre a escrita autoficcional de Salim Miguel e a instauração de um pacto ambíguo com o leitor, a partir dos pressupostos teóricos de Lejeune (2008), Arfuch (2007), Alberca (2007) e outros. Nesses termos, por uma via que privilegia a relação intrínseca entre diferentes textos do mesmo autor e abarca tanto a análise textual quanto paratextual, identificou-se na produção literária do escritor líbano-catarinense a utilização de uma série de procedimentos que desconfiam de noções centralizadoras como as de sujeito, identidade e pretensão de totalidade.
\end{abstract}

Palavras-chave: Espaço autoficcional. Infância. Pacto ambíguo.

Paradigma do gênero autobiográfico, as Confissões, de Jean-Jacques Rousseau, livro escrito entre 1764 e 1770, emprega uma causalidade psíquica que é exemplar às escritas do eu: para conhecer o adulto é preciso aprender a vê-lo na infância, pois a criança é o pai do homem. Neste sentido, a infância deixa de ser percebida apenas como a época dourada cantada pelos poetas românticos para configurar-se também em um princípio de compreensão acerca do comportamento adulto e possível causa das apreensões e dificuldades vivenciadas posteriormente.

É exatamente esse período da vida enfocado nos livros Onze de Biguaçu mais um (1997) e Reinvenção da infância (2011), do escritor líbano-catarinense Salim Miguel. Tais narrativas apresentam, entre os percalços da infância e da juventude, uma espécie de percurso de formação pessoal, moral e literária do filho mais velho do Seu Zé Miguel, personagem

\footnotetext{
${ }^{1}$ Doutora em Estudos Literários pela Universidade Federal de Santa Maria e Professora de Língua Portuguesa e Literatura, do Instituto Federal de Educação, Ciência e Tecnologia Farroupilha (IFFAR-RS), RS, Brasil. E-mail: clauoli13@gmail.com. (i) https://orcid.org/0000-0002-8150-6956
} 


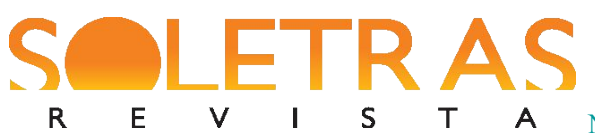

N. 38 - 2019.2 - ANA CLÁUDIA DE OLIVEIRA SILVA

construída pelo autor para ficcionalizar a própria experiência. Neste contexto, poderíamos inseri-los no modelo do Bildungsroman, uma vez que portam uma série de elementos, nos quais a experiência vivida, com os seus conflitos, sofrimentos e mudanças, torna-se fundamental na formação do sujeito adulto, elaborando uma espécie de sentido para a sua vida.

Esse sentido está diretamente relacionado à construção narrativa, pois, como afirma Paul Ricouer (1994), o homem somente é capaz de compreender o tempo quando o organiza sob a forma de um relato. Podemos afirmar com base nisso, tanto a impossibilidade de compreender o tempo fora da esfera humana, quanto a necessidade de narrar um acontecimento passado para conferir sentido ao que foi vivido e, desse modo, possibilitar ao sujeito constituir-se como tal.

Tal esforço reflexivo e constitutivo é perceptível nas narrativas de Salim Miguel aqui apresentadas, contudo, ao realizar esse empreendimento e tentar organizar o tempo da infância em um enredo, o escritor parece não alcançar plenamente uma totalidade significativa, capaz de reconfigurar a "própria experiência temporal confusa, informe e, no limite, muda" (RICOUER, 1994, p.12). Talvez por essa razão, ele retorne em Reinvenção da Infância aos mesmos acontecimentos narrados em Onze de Biguaçu, buscando, dessa forma, quem sabe, perceber o que está ausente ou o que escapa à própria compreensão.

Nesta perspectiva, partimos da hipótese de que a repetição de cenas literárias e personagens constrói uma espécie de "espaço autoficcional", ${ }^{2}$ local onde o escritor, atravessado pela experiência da diáspora, pode expressar-se livremente. Em outras palavras, um espaço de reconfiguração da experiência habitado/compartilhado por uma variedade de textos que dialogam entre si e também com a biografia do autor, assinalando o fato do sujeito não poder ser redutível a nenhum deles. Tal hipótese apoia-se, ademais, na compreensão do conceito de autoficção como o relato pessoal feito pelo autor com plena consciência do caráter discursivo (no sentido de construção de linguagem) que a escrita de si assume, mas

\footnotetext{
${ }^{2} \mathrm{O}$ conceito de "espaço autoficcional", a semelhança dos conceitos de "espaço autobiográfico", de Philippe Lejeune (2008), e de "espaço biográfico" proposto por Leonor Arfuch (2007), refere-se à possibilidade de um diálogo intertextual entre diferentes narrativas de um mesmo autor. Para Lejeune, essa zona não claramente definida destaca o fato de o sujeito autor não ser redutível a nenhum de seus textos autobiográficos, podendo ser reconhecido também em variados elementos fantasmáticos presentes em seus textos ficcionais. Já para Arfuch, o conceito expande-se para compreender todo o espaço compartilhado pelas escritas de si na contemporaneidade, apontando para a coexistência intertextual de diversos gêneros discursivos em torno de posições de sujeito autentificadas por uma existência "real", em outras palavras, "un singular habitado por la pluralidad" (2007, p.248).
} 
que, mesmo assim, decide "jogar" com os vestígios referenciais, borrando as fronteiras entre os dois discursos: autobiográfico e romanesco.

Nessa perspectiva, importa refletir sobre a possibilidade de haver ou não algum tipo de aprendizado nesse processo e, em caso afirmativo, qual o sentido apreendido sobre a própria existência ao realizá-lo. Bem como inferir se a imagem oferecida ao leitor é idêntica em cada um desses livros ou sempre dessemelhante, visto que são os mesmos pedaços de vida, porém dispostos de outra maneira.

\section{A reescrita obsessiva da infância: "ficções"}

Salim Miguel não escreve, ele reescreve. Os seus textos consistem em uma reescrita obsessiva de fragmentos da própria infância que, obstinadamente, teimam em retornar para o sujeito adulto. São os mesmos pedaços de vida, mas sempre diferentes. Processo narrativo que parece apontar para a criação de uma obra única, em que histórias e personagens só se dão a conhecer a partir do seu aspecto relacional. Sendo assim, importa retomar certa reflexão sobre a recriação da infância, retirada de A morte do tenente e outras mortes:

\footnotetext{
Vou retroceder, erguer a minha infância morta e das cinzas recriar um mundo perdido de sensações e emoções, de busca. Reconstituir passo a passo, cheiro a cheiro, sabor a sabor, prazer a prazer, as sombras do ontem. Até aqui, e agora, me chega o perfume do que não é mais. Aspiro-o. Quero-o de volta, íntegro, e fixar nele um instante, parado no tempo, fixá-lo e retê-lo para sempre, gravar dele um instante fugaz. (MIGUEL, 1979, p.112)
}

Essa busca de um "instante fugaz" expressa bem o que percebemos nos livros selecionados e parece imiscuir-se na forma narrativa de ambos. Dessa maneira, em que pese à presença da mesma personagem, o filho do Seu Zé, e a configuração espacial, Biguaçu, tais narrativas apresentam uma estrutura fragmentada, cujos capítulos funcionam também como unidades autônomas. Por conta disso, é possível transpor contos inteiros de Onze de Biguaçu para Reinvenção da infância, numa espécie de construção-reflexo, que, ao mesmo tempo, retoma o já dito e expande a sua compreensão, ao acrescentar informações e unir pedaços de 


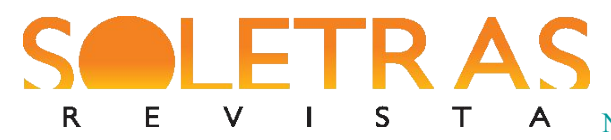

um texto no outro. Isso causa a impressão de uma obra fragmentada e inacabada, que está sempre a refazer-se e remete incessantemente para si mesma.

Nesse labirinto narrativo o autor plasma literariamente a tentativa sempre incompleta do homem contemporâneo em recompor uma subjetividade cindida por meio da identificação com o outro. O retorno à infância não se limita, assim, à procura de um sentido existencial único, compreensível através da racionalidade e, portanto, capaz de abarcar a totalidade de uma vida; ao contrário, constitui-se de pequenos "instantes fugazes" vividos em sua plenitude e, por isso, passíveis de suspender o tempo linear e progressivo da história.

Para isso, ele elege o fragmento, o descontínuo e a repetição de pequenos pedaços de sua infância, desvinculando-se subjetivamente deles na escrita. Tal como sugere a epígrafe de ambos os livros, retirada do conto "Tlön, Uqbar, Orbis Tertius", de Jorge Luis Borges:

Aqui dou término à parte pessoal do meu relato. O resto está na memória (quando não na esperança ou no temor) de todos os meus leitores. É suficiente para mim recordar ou mencionar os fatos subsequentes com mera brevidade de palavras que a côncava lembrança geral enriquecerá ou ampliará.

Essa epígrafe aponta para o conceito borgeano de ficção como mescla entre o empírico e o imaginativo, como sugerem o substantivo reinvenção no título de um dos livros e o paratexto "ficções" grafado na contracapa do outro (Onze de Biguaçu). Ademais, ela também indica a necessidade de participação do leitor nesse processo de construção ficcional, cabendo-lhe preencher os espaços em branco, os vazios deixados pela memória. Para tal, muitas vezes, utiliza-se de comentários reflexivos sobre aquilo que é contado, instaurando uma perspectiva dialógica e informal, como nesses exemplos: “[...] vi na rua um patacão rebrilhando (ou este rebrilhando é acréscimo recém-incorporado?)” (MIGUEL, 1997, p.19 / MIGUEL, 2011, p.23); “[...] a mãe, com pena do filho, então alguém mais esperto e sem teus escrúpulos (o escrúpulos seria mesmo palavra da mãe, ou componente novo agora também incorporado?)" (MIGUEL, 1997, p.23 / MIGUEL, 2011, p.26).

Neste sentido, ao procurar identificar-se com o outro da escrita - o leitor que recebe e recria o universo produzido na narrativa -, a figura autoral parece desapegar-se de sua função demiúrgica em direção a algo mais vasto. Aliás, Salim Miguel, em uma de suas entrevistas, 
critica a palavra "romance" justamente por acreditar que o romance convencional, que apenas dá o seu recado digestivo e não mexe com o leitor, está esgotado.

Essa interpretação é reforçada pela temática de ambos os livros, pois ao eleger a infância - momento particular e também universal da experiência humana -, o escritor aparenta optar por uma temporalidade vivida em comunidade, no encontro com o outro durante o processo mesmo de reconhecer-se como sujeito. Conforme ele bem expressa na "Nota final" de Reinvenção ao esclarecer o designativo genérico "filho do Seu Zé": “o protagonista, intencionalmente, não tem nome, pois o ser humano em qualquer época e em qualquer parte do mundo tem instantes de aproximação; na sua infância, da infância dos demais" (MIGUEL, 2011, p.126).

O primeiro episódio apresentado nas narrativas é, nessa perspectiva, sintomático: refere-se ao processo de partir, de deslocar-se de um lugar conhecido para outro e iniciar um novo percurso de vida. Em Onze de Biguaçu, a mudança é pequena, dentro do mesmo município: de Alto Biguaçu para a sede Biguaçu. O acontecimento é relatado inicialmente por meio da perspectiva inusitada da cachorra da família, cujo nome dá título à ficção, "Taira". Valendo-se, portanto, de uma focalização interna limitada, o narrador vai pouco a pouco apresentando pistas ao leitor para que esse compreenda o porquê do movimento incomum na casa, a bagunça, a desarrumação. E, de modo imperceptível, o foco muda para o filho mais velho de Yussef ao relacionar os sentimentos comuns da cachorra aos demais filhos do casal Miguel: perplexos, indóceis, diante da nova mudança. Até que ela se concretize, deixando para trás não apenas a companheira de brincadeiras infantis, Taira, mas um pouco das esperanças, sonhos e expectativas de uma vida melhor.

Logo a estranha caravana se perde numa curva, a família de novo ciganando, destino outro município, não-não, o mesmo, só que agora a sede, agora Biguaçu, onde tudo recomeçaria, sempre esperanças renovadas de melhores dias, vãs esperanças, sempre sonhos e sonhos se diluindo, embora dissessem para si mesmos e para os outros, desta vez vai dar certo, dar certo, certo. (MIGUEL, 1997, p.13-14).

Em Reinvenção da infância, o processo de partir principia e fecha o relato fragmentado da infância do filho do Seu Zé Miguel. O primeiro capítulo, intitulado "Vão", mistura a lenda do gigante de quase três metros de altura contada pelo preto velho Ti Adão e a viagem de navio realizada por escravos e imigrantes antes de chegar ao Brasil. É importante 
frisar que a compreensão dessa lenda só foi possível por meio da leitura de Nur na escuridão, livro em que ela é apresentada da seguinte forma:

Para os filhos de dona Tamina e seu Zé, longe de alcançarem o sentido de tais fábulas, o que mais os fascinava e intimidava era a lenda do gigante de quase três metros (em certas ocasiões aumentava para cinco), escondido no teto do casarão mal-assombrado, que começava urrando antes de cair aos pedaços, primeiro a cabeça, depois o pescoço imenso, depois as pernas ficavam correndo sozinhas com a cabeça reclamando me-espere-me-espere pelo resto, depois os braços que lutavam por agarrar as pernas, mas cadê as faltantes mãos e os invisíveis dedos, depois os cabelos, depois as unhas chorando, quero meus dedos... Ti Adão parava, naquelas pausas angustiantes, pedia: outra pinga, seu Zé, pra amaciar a garganta, tou com sede.

Aqui, por igual, retomava ou não o causo, que vinha se desenrolando aos pedaços, que nem a fragmentada queda do corpo... (MIGUEL, 2004, p.207-208).

E, de modo semelhante ao "causo, que vinha se desenrolando aos pedaços, que nem a fragmentada queda do corpo...” (MIGUEL, 2004, p.208), o livro estrutura-se em frações, cujos episódios funcionam como módulos independentes ou ainda como pequenos contos, cuja união poderá fornecer apenas uma imagem igualmente despedaçada da personagem principal. Da mesma forma, ao relacionar lenda e deslocamento de povos, podemos pensar a saída da terra de origem como um processo doloroso, em que há uma fratura indelével no modo de ser e sentir desses sujeitos, cindidos identitariamente.

Rejuntados os pedaços a figura vai minguando até se tornar quase invisível no assoalho de madeira encerada, logo volta a crescer chegando até as telhas, ao mesmo tempo em que o casarão já não mais é, o navio trazendo no porão imigrantes e escravos zarpa de um porto ignoto para um destino igualmente ignoto, enquanto a mesma voz reboa vamos, vamos, vamos, rápido, para o ontem, para o hoje, para o amanhã. Vamos, vamos, vamos. E vão. (MIGUEL, 2011, p.13).

É necessário rejuntar os pedaços e empreender uma viagem no tempo em busca de algo que ficou perdido nesse processo, preencher um vazio existencial. Torna-se significativo, portanto, a exortação, "vamos, vamos, vamos, rápido, para o ontem, para o hoje, para o amanhã", a qual convida o leitor a empreender a mesma viagem e permite antever a fórmula: rever o passado, para pensar o presente e intuir/projetar outro futuro. 
Já no capítulo final, "Diálogo singular", o narrador vale-se novamente de uma perspectiva inusitada ao apresentar o processo de uma nova mudança - agora, para a capital do Estado, Florianópolis - por meio do diálogo entre os dois animais da família: a cachorra Taira e o cavalo Sultão. O período, $2^{\text {a }}$ Guerra Mundial; o motivo, dificuldades financeiras: “eu ouvi o rapazote dizendo: meu pai agora acha que não dá mais mesmo, com a guerra aí, nem troca de gêneros o pai consegue, é só fiado" (MIGUEL, 2011, p.120). E Taira termina o diálogo afirmando: "Calma, tamos botando a carroça na frente do cavalo, hoje não vai ter mudança”. Ao que Sultão rebate: “Tomara que nem amanhã” (MIGUEL, 2011, p.120).

Aliado ao tema da movência avulta a questão identitária e os seus conflitos, ou antes, o símbolo da falta que tal vinculação abarca. A unidade que trata dessa questão intitula-se "É turco" e é transposta de um livro ao outro sem qualquer alteração. Nela, o narrador relata a difícil adaptação no ambiente escolar do filho do Seu Zé, recém-chegado a Biguaçu, visto que o menino é matriculado sem nada conhecer do idioma da terra de chegada. Depois de alguns meses, a professora chama a atenção da classe e:

Diz apontando para ele: olhem só, olhem e se mirem no exemplo, há pouco não sabia uma só letra, não conhecia uma única palavra do português, mal falava um precário português misturado com árabe e alemão, é turco, e já sabe ler e escrever melhor do que quase todos, ou todos, aqui dentro. (MIGUEL, 1997, p.17 / MIGUEL, 2011, p.20, grifo nosso).

Todavia, o elogio inesperado, ao invés de proporcionar prazer, causa um choro desenfreado no personagem:

E o filho do seu Zé, do Zé Turco, do Zé Gringo, do seu Zé da venda, raramente seu Zé Miguel, nunca seu José, desaba num choro ferrado, interminável, incontrolável, fundos soluços, lágrimas escorrendo, o que causa risos nos colegas e espanto da professora. (MIGUEL, 1997, p.17 / MIGUEL, 2011, p.20).

Choro inexplicável, o qual ele não consegue decifrar por mais que se esforce. Talvez o designativo turco: "a família era libanesa; querer irritar o pai (mais que a mãe), era chamá-lo 
de turco. A Turquia (Império Otomano), durante dezenas de anos, havia dominado toda uma região que incluía Síria e Líbano” (MIGUEL, 1997, p.17 / MIGUEL, 2011, p.20).

A explicação talvez esteja no símbolo da falta, do vazio do pertencimento, pois se, para o pai, a identidade libanesa ainda estava muito latente, para o filho, essa questão é muito mais complexa: descende de uma cultura, a árabe, da qual pouco conhece; reside em localidades do sul do Brasil, cuja predominância é de imigrantes alemães, com os quais procura identificar-se sem sucesso; tem que aprender outra cultura, costumes e língua do país onde reside, mas é visto quase sempre com curiosidade, como um ser estranho, muitas vezes exótico. Em outras palavras, para o filho do Seo Zé, a sua identidade permanece contextualmente irresolvida, enquanto que, para a professora e os demais colegas, ele é o outro, um ser diferente e, nessa linha interpretativa, cultural e intelectualmente inferior aos demais.

O "elogio", nesse caso, apenas reforça o distanciamento e aponta para a rejeição daquele que não é igual a mim. Em contrapartida, a sua identificação com o indiozinho, filho adotivo do Seu Fermiano, ${ }^{3}$ ao mesmo tempo, tão diferente e tão semelhante a ele no que tange à questão do pertencimento, aponta para o estabelecimento de um espaço de coabitação, o qual não consiste, obviamente, em tornar-se o outro, mas aceitá-lo. E a relação entre os dois dá-se em meio às brincadeiras infantis, através das quais ambos buscavam manter as suas tradições culturais:

\footnotetext{
Os dois meninos estavam cada vez mais amigos, brincavam por toda a Alto Biguaçu, aventuravam-se até mais adiante no caminho de Biguaçu ou de Rachadel, porém do que mais gostavam era de brincar com barro, ficavam horas entretidos, o bugrinho tentando fazer uma piroga e um remo, um papagaio, o turquinho, lembrança de lembranças dos pais, simulacro de um cedro do Líbano, ou um bolinho, que ele brincava dizendo comam um pedacinho de quibe. (MIGUEL, 2011, p.16).
}

Indiferentes aos problemas decorrentes da imposição de uma única cultura, cabe ao pai refletir sobre a situação dos meninos: "Seo Zé calculou: o filho mais velho devia ter mais ou menos a mesma idade do indiozinho, um viera do outro lado do mundo, a família em busca de um chão, o outro já nem tinha mais o chão que era dos seus" (MIGUEL, 2011, p.16).

\footnotetext{
${ }^{3}$ Em "Outubro, 1930", o pai adotivo do indiozinho será o personagem de Chico Setúbal e o nome do filho Firmino. Em Reinvenção da infância, o nome do pai confunde-se com o filho, sofrendo uma pequena alteração gráfica: Fermiano.
} 


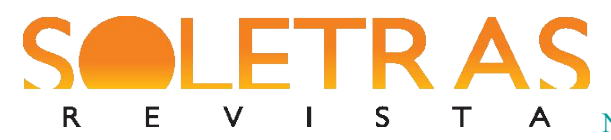

Outra vez ressalta-se a relação entre o espaço físico e a questão da identidade, da vinculação afetiva a um lugar, um território, em que o sujeito possa fixar as suas raízes. Todavia, a trajetória nômade da família Miguel, frequentemente, comparada ao movimento itinerante dos ciganos, faz com que essa busca nunca se concretize no plano físico, apenas por meio da imaginação, da construção fictícia de uma cidade, no caso Biguaçu, ao mesmo tempo, mítica e real.

Assim, ao erigir pequenos instantes fugazes do passado, o narrador passa a reviver novamente, através do personagem do filho do Seu Zé, a infầncia perdida para sempre no tempo. Nesse processo, ganha materialidade a palavra Revolução e a vitória de Getúlio Vargas, das quais o personagem guarda apenas fragmentos esparsos; a lição de realidade aprendida ao encontrar um patacão de dinheiro na rua e a sua perda provavelmente a um outro, sem os seus escrúpulos; a primeira bebedeira; os primeiros namoricos; as brincadeiras; os amigos; o susto ao ser projetado para o alto depois de um corcoveio do cavalo Sultão; a descoberta do sexo; as brigas e os desentendimentos; o fascínio pelo cinema e, durante a $2^{\mathrm{a}}$ Guerra Mundial, as patrulhas à procura de espiões alemães, a visão do Zeppelin, a bomba que acertou a fachada da farmácia de Seu Taurino.

\section{Fato ou ficção: ambiguidade narrativa}

Em meio a essa sucessão infindável de instantes eternos, gravados para sempre na memória, sobressai-se, em ambos os livros, a formação literária do protagonista, um ávido e curioso ouvinte e leitor. Essa formação é alimentada pelas muitas leituras em voz alta realizadas para o poeta cego João Mendes, dono da única livraria em Biguaçu, dentre as quais se destacam: No Curdistão bravio, de Karl May; O mandarim e O primo Basílio, de Eça de Queirós; OTronco do Ipê, de José de Alencar; La vida és sueño, de Calderón de La Barca; $O$ conde de Monte Cristo, de Alexandre Dumas; Robinson Crusoé, de Daniel Defoe; e A toutinegra do moinho, de Emilio Richebourg.

Da mesma forma, influi de modo preponderante a tradição dos contadores orais Yussef-José e Ti Adão -, com as suas impressionantes e fantasiosas histórias, bem como a milenar cultura árabe: os contos das Mil e uma noites, que os pais contavam nos serões 
noturnos,as fábulas orientais do Falso árabe, ${ }^{4}$ os poetas Omar Khayam, Rubayat, Hafiz, Saadi, Fauze Maluf e o profeta Gibran Kalil Gibran, cujos versos eram sempre recitados no ambiente familiar.

Dessa maneira, de ouvinte e leitor, o personagem passaria a nutrir o desejo de ser também um contador de histórias:

[...] o primogênito do seu Zé, molecote siderado pelas histórias onde fantasia e realidade se fundiam/confundiam, fascinado pela maneira de contar, pelos rodeios, por uma busca de suspense, misturando-as com as narradas pelo pai, pela mãe, mais adiante comparando-as com as inumeráveis leituras que passara a fazer, de início devorando tudo que encontrava em casa, bem pouco, a maioria em árabe, lia até anúncios de jornal e receituários médicos para saciar sua fome, apelou para as parcas bibliotecas particulares, para os livros do Grupo Escolar Professor Brasilício de Souza, até a mágica descoberta da mina inesgotável na livraria do João Mendes, cego e poeta, com igual e inesgotável sede de saber, e de quem se tornou leitor, em leituras que se prolongavam por horas, durante anos. (MIGUEL, 1997, p.38).

A "escenificação" do ato de ler e a presença do mentor ou guia que dirige as leituras juvenis são recorrentes na produção de autores que se voltam para a própria infância, como é o caso de Salim Miguel. Segundo Sylvia Molloy (1996), essa estratégia é comum nos livros autobiográficos de escritores, pois, para esse sujeito, os livros são a vida real, ou melhor, o encontro com a palavra escrita representa simbolicamente o começa da sua história pessoal:

I - Ainda analfabeto, ele já se deixara encantar por aqueles signos mágicos que certamente iriam lhe desvendar novos e fascinantes mundos, repletos de peripécias e travessuras. Ficava olhando os velhos jornais, a revista Oriente que o pai recebia de São Paulo, chamava a mãe, dizia: "me diz que palavra é esta", e ela, "me deixa trabalhar, na escola ficarás sabendo que palavra é”. (MIGUEL, 2011, p.99).

Ser alfabetizado significou, portanto, para o menino curioso a realização de um sonho, levando-o, ao mesmo tempo, à obsessão pela leitura: “[...] logo estava grudado nos velhos jornais, na revista, em almanaques e até na bula dos remédios. Era pouco, queria mais [...]” (MIGUEL, 2011, p. 99). Essa "sede" insaciável somente seria aplacada com a contraproposta

\footnotetext{
${ }^{4}$ O Falso árabe citado em Reinvenção da infância era Malba Tahan, pseudônimo do matemático brasileiro Júlio César de Mello e Souza.
} 
de João Mendes para que o jovem lesse em voz alta alguns livros para ele, acordo que se estendeu durante anos, "numa dieta variada e confusa...". Mesmo assim, para o filho do Seu Zé e da dona Tamina não bastava ler, "é necessário que o objeto livro passe a fazer parte física de sua vida, que o tenha para sempre diante dos olhos, à mão para tocá-lo, senti-lo, cheirá-lo, mesmo depois de lido e relido" (MIGUEL, 1997, p.20 /MIGUEL, 2011, p.24).

$\mathrm{O}$ vivido e o lido são categorias complementares para o personagem, como também o são para o escritor autobiógrafo e para aquele que se vale do discurso autobiográfico em sua ficção, como esclarece Silviano Santiago em Meditação sobre o ofício de criar:

Ao reconhecer e adotar o discurso autobiográfico como força motora da criação, coube-me levá-lo a se deixar contaminar pelo conhecimento direto - atento, concentrado e imaginativo - do discurso ficcional da tradição ocidental, de Miguel de Cervantes a James Joyce, para ficar com extremos. [...] Com a exclusão da matéria que constitui o meramente confessional, o texto híbrido, constituído pela contaminação da autobiografia pela ficção - e da ficção pela autobiografia -, marca a inserção do tosco e requintado material subjetivo meu na tradição literária ocidental e indicia a relativização por esta de seu anárquico potencial criativo. (2008, p.174).

O mesmo pode-se afirmar em relação à produção de Salim Miguel, pois o discurso autobiográfico presente em sua escrita é constantemente contaminado pelo discurso ficcional da tradição literária, ocidental e oriental, ou ainda, como gostaríamos de salientar, pelo discurso do ensaísta e crítico literário. O que resulta em um texto híbrido que se alimenta, de modo concomitante, da experiência de vida do escritor e da reflexão sobre as suas leituras.

Com base nisso e considerando que, para Salim Miguel, a infância faz de nós o que somos hoje, concluímos que é, na infância, que ele constrói o seu "mito de escritor", tal como se encontra sugerido na ficção "Câimbra". Nesta última, o narrador relata os pensamentos e sensações vividos pelo personagem antes, durante e depois de um quase afogamento. Por conta desse fato, o filho do Seu Zé apresenta momentos de delírio e lucidez, que, num processo recorrente na produção do autor, faz com que a voz do narrador, em terceira pessoa, aparentemente afastado da história, alie-se a do personagem, confundindo-se com ele:

[...] afunda, afunda, afunda, não pode ser, não quer, não quero, lamenta-se, toda uma vida diante de mim, vislumbra o futuro, antevê-se no futuro, o que será, não 
comerciante como o pai, jogador de futebol, emérito nadador, talvez venha a escrever. (MIGUEL, 1997, p.40, grifo nosso).

Essa confusão reverberana questão da identidade entre autor-narrador-personagem principal, uma vez que existem elementos que permitem essa identificação, como sugere a conjugação do verbo "querer" na $1^{\text {a }}$ pessoa do singular do presente do indicativo e o segmento narrativo "talvez venha a escrever", ainda que, concomitantemente, também o neguem por meio da suspeição do discurso pessoal, proferido em meio ao delírio de um quase afogamento, e da utilização da $3^{\text {a }}$ pessoa. Sendo assim, ainda que um narrador em primeira ou em terceira pessoa seja apenas uma máscara criada, adotada e mantida pelo autor, podemos perceber que essa alternância entre as pessoas do discurso não é aleatória, mas aponta para uma fissura entre o sujeito do enunciado e o sujeito da enunciação, entre personagem-escritor e narrador.

Nessa mesma linha interpretativa, importa destacar que a confusão de vozes enunciativas, a qual desestabiliza o discurso do narrador e coloca em suspeição a ideia mesma de uma identidade constante no tempo, aparece justamente no momento em que a instância narrativa interroga-se sobre o "eu" e a sua trajetória futura de vida. Questionando-se, logo adiante no texto, sobre a sua posição e de seus ambiciosos sonhos diante da realidade familiar:

\begin{abstract}
A mãe chama-o, sua voz se contrapõe ao outro chamado, que volte, que não a deixe, aquele mãe tão sofrida, o doce rosto tenso debruçado sobre ele, as lágrimas, o soluçar; o pai afasta-a, consola-a, aquele pai sempre adoentado, sem nenhuma vocação para o comércio, o que fazer além disso, pior a opção da mascateagem; os irmãos atônitos cochichando. Onde nesse quadro ele e seus ambiciosos sonhos? (MIGUEL, 1997, p.40).
\end{abstract}

Questionamento que talvez explique o designativo "filho do Seu Zé", pois ao regressar às memórias da infância, o protagonista busca situar-se e, simultaneamente, afirmar-se, com as suas aspirações e desejos futuros, em meio às atribulações familiares. Dessa maneira, ao projetar-se como personagem de sua própria ficção, o "eu", nesse caso mascarado em um "ele", busca a identificação com os Outros, aqueles com os quais compartilha a experiência de estar no mundo (ARFUCH, 2007). 
Nessa perspectiva, do mesmo modo que acontece ainda em cidades pequenas do interior do Brasil, o protagonista é identificado por um designativo que alude à sua descendência: ele é o filho primogênito dos Miguel. A sua condição de filho é o que o identifica e caracteriza nesse momento da vida. Portanto, a falta de um nome próprio, juntamente com a utilização de uma aparente terceira pessoa, não impossibilita a identificação do protagonista e a sua aproximação com o autor Salim Miguel, visto o uso do mesmo sobrenome e a relação filial com Yussef-José Miguel.

Sustentamos com base nisso, que, nos dois livros, o pacto instaurado com o leitor é ambíguo (ALBERCA, 2007), ${ }^{5}$ pois ao mesmo tempo em que se reforça a ficcionalidade do que é contado, por outro lado, há indicadores textuais sugerindo uma leitura supostamente autobiográfica, como a confusão entre as vozes do narrador e do personagem, a inclusão de dados biográficos (nomes dos pais, cidades onde morou, "vinculação" identitária, interesses, futura profissão), além do designativo nominal utilizado: filho do Seu Zé Miguel.

Essa ambiguidade narrativa possibilita ao escritor livrar-se daquilo que Pierre Bourdieu conceitua de "ilusão biográfica", ou seja, a percepção da história de vida, assim como do seu relato, como um caminho com começo, meio e fim, evolutivamente desenvolvidos. O sociólogo adverte que, para fugir de tal ilusão retórica, é necessário desvincular a noção de trajetória à identidade proporcionada unicamente pelo nome próprio, considerando em contraponto como essa mesma noção estrutura-se. Ele propõe que "os acontecimentos biográficos se definem como colocações e deslocamentos no espaço social" (BOURDIEU, 2006, p.190), pois uma trajetória somente pode ser compreendida caso construa-se previamente os estados sucessivos do campo no qual ela desenvolveu-se, bem como o "eu" não pode ser dissociado do "conjunto dos outros agentes envolvidos no mesmo campo e confrontados com o mesmo espaço dos possíveis" (BOURDIEU, 2006, p.190). Isso significa que o sujeito não é uma “constância em si mesmo", mas engendrado pelas relações e posições que ocupa em um determinado tempo e lugar no espaço social.

Ao partir dessa constatação, interessa perceber que, aliado ao designativo filiar, em Reinvenção da infância, temos também a inserção do nome do autor. Isso acontece em dois

\footnotetext{
${ }^{5}$ De acordo com Alberca (2007), a autoficção pretende romper com os esquemas receptivos do leitor ou, ao menos, fazê-lo vacilar, duvidar do que lê, ao propor um pacto romanesco, por um lado, e sugerir uma leitura autobiográfica, por outro. Essa leitura contraditória, que o autor abarcará sob o conceito de "pacto ambíguo", deriva da identificação nominal autor-protagonista (explícita ou implícita), a qual insinua, de maneira confusa, que esse personagem é e não é o autor - identidade imprecisa que borra as fronteiras entre o factual e o fictício ao apontar para o caráter não mimético da criação literária e, simultaneamente, para o lugar da sua produção.
} 
momentos específicos, ambos relacionados com a profissão que o personagem gostaria de desenvolver quando adulto, isto é, o nome próprio aparece vinculado estritamente à funçãoautor $^{6}$ (FOUCAULT, 2009).

A primeira está presente no capítulo "Dois minutos" e refere-se ao primeiro texto ficcional escrito pelo filho do Seu Zé, que assina logo depois do título: "S.M.”:

Figura 1 - Imagem do manuscrito do texto intitulado "Dois minutos"

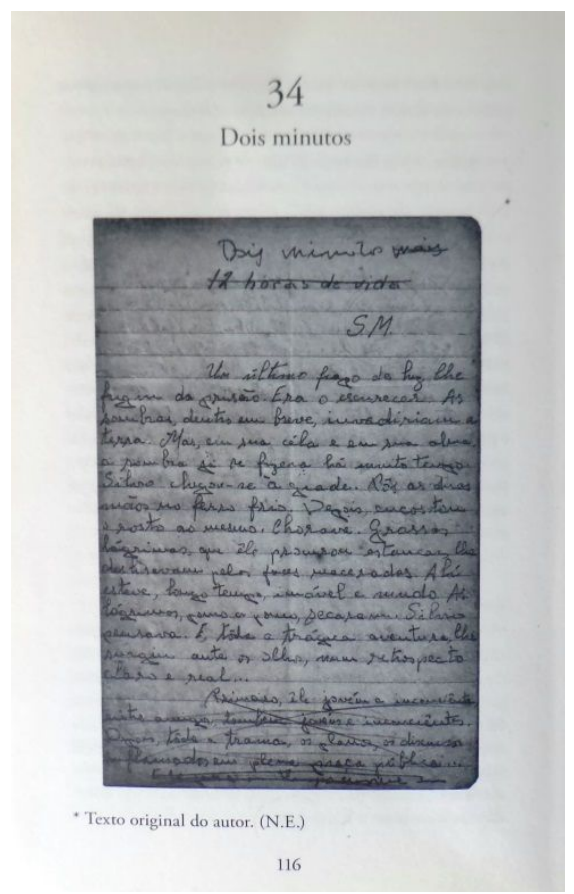

Fonte: MIGUEL, 2011, p.116.

A segunda referência está em um capítulo intitulado "Apêndice", que funciona como um resumo dos anseios, desejos e preocupações do "futuro escriba". Nele, o narrador realiza uma espécie de percurso, o qual começa com a alfabetização das primeiras letras, a

\footnotetext{
${ }^{6}$ Michel Foucault, em O que é um autor? (2009),reflete sobre os diferentes dispositivos a partir dos quais, em um determinado tempo e espaço, tornou-se não apenas possível como necessário atribuir a certos enunciados um nome. Dessa forma, ao traçar a genealogia da figura moderna do autor, ele chega à conclusão que essa categoria é antes de tudo uma invenção, surgida juntamente com as noções de propriedade privada e lucro no bojo da burguesia e do capitalismo. Nessa perspectiva, como categoria que não existe a priori nem é conferida a todos os tipos de textos ou a seus produtores, deve-se considerar o autor como uma função complexa e variável do discurso, que não remete necessariamente para o sujeito escritor ou para o momento em que ele escreve. Ele propõe, então, para preencher o lugar deixado vago pelo desaparecimento do autor empírico, o conceito de função-autor, que "é característica do modo de existência, de circulação e de funcionamento de certos discursos no interior de uma sociedade" (2009, p.274).
} 
curiosidade e o interesse em saber mais, o gosto por realizar associações de palavras, a preocupação com o ritmo e a economia no dizer, as primeiras tentativas ao aventurar-se a contar uma história:

A primeira vez que tentou contar uma história, não se deu bem. Tratava-se de um fato ocorrido durante uma aula: a professora chamou um aluno ao quadro-negro e mandou que escrevesse a frase "por ser mais aquinhoado, não devo me julgar superior" e repetisse a mesma cem vezes no caderno escolar [...]. O caso é que, embora sussurrado, toda a classe e a professora haviam escutado aquele "seu negrinho sarnento", dirigido ao colega. Ele não conseguiu reconstituir por escrito o incidente com toda a sua carga ofensiva e racista. (MIGUEL, 2011, p.122-123).

O seu intuito é transformar-se em um contador de histórias, como o "preto velho $\mathrm{Ti}$ Adão" e os seus causos fabulosos. Figura enigmática nos seus quase cem anos, que passou a marcar presença constantemente na produção ficcional do escritor Salim Miguel. Outra é a mãe de Pedro Maria, sofrida mulher que se sujeitava à prostituição para sustentar o filho deficiente, nascido com uma deformação craniana. Nesse caso, o narrador destaca:

\begin{abstract}
Sem outra preocupação que não a de relatar o que aquela sofrida mulher contava dela e do filho "tanso", rascunhou a história. Voltou a ela em 1943, já residindo em Florianópolis, porém só foi publicada mais tarde; embora já preocupado não apenas em contar uma história, mas também com a maneira de contá-la, não mexeu no texto. Jamais pensou re-editá-la, no entanto eis aqui cinco trechos, com suas impropriedades: (MIGUEL, 2011, p.124).
\end{abstract}

$\mathrm{Na}$ sequência, apresentam-se cinco fragmentos relacionados à tentativa, sempre incompleta, de captar o interior dessa personagem, de prever-lhe os sentimentos, as angústias, os problemas diários. O primeiro possui como título "A mãe de Pedro Maria", o segundo "Alguma gente" e o último, "SALIM MIGUEL", datado de abril de 1953. Obviamente, o escritor possui um conto intitulado "A mãe de Pedro Maria”, em seu livro Alguma gente, publicado em 1953: 


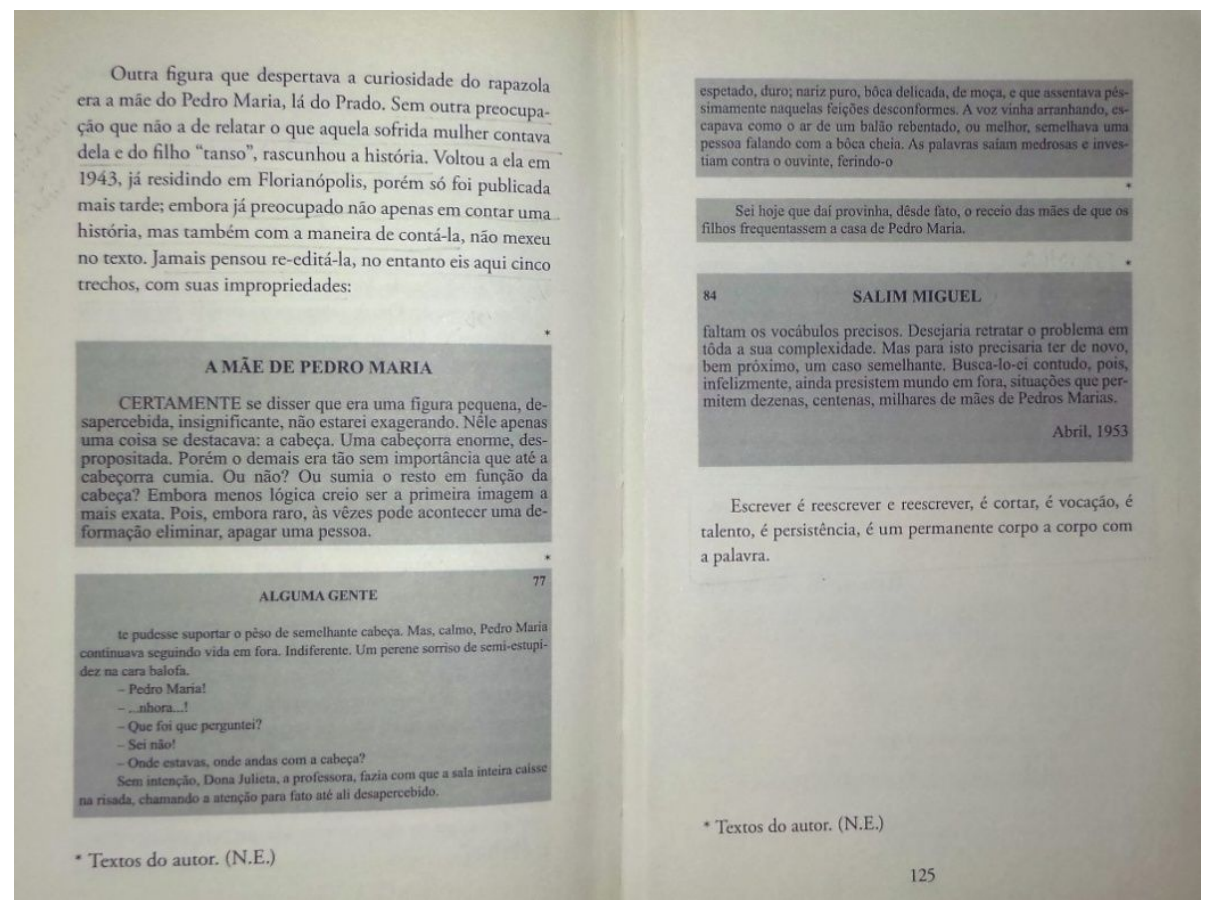

Fonte: MIGUEL, 2011, p.124-125.

Aliado a isso, todos esses fragmentos e o texto "Dois minutos" vêm acompanhados de notas de rodapé, em que se lê: "Texto original do autor. (N.E.)". Conforme se depreende da abreviatura "N.E." (Nota do Editor), essas notas foram incluídas posteriormente durante a edição do livro. Constituem-se, portanto, em um paratexto que envolve o texto literário, mas também o conforma, indicando modos de leitura e recepção.

De acordo com Gerard Genette (2010), um texto pode estabelecer diferentes tipos de relações transtextuais, como a intertextualidade, a metatextualidade, a arquitextualidade, a hipertextualidade, a paratextualidade. Esta última constitui-se:

[...] pela relação, geralmente menos explícita e mais distante, que, no conjunto formado por uma obra literária, o texto propriamente dito mantém com o que se pode nomear simplesmente seu paratexto: título, subtítulo, intertítulos, prefácios, posfácios, advertências, prólogos, etc.; notas marginais, de rodapé, de fim de texto; epígrafes; ilustrações; release, orelha, capa, e tantos outros tipos de sinais acessórios, autógrafos ou alógrafos, que fornecem ao texto um aparato (variável) e por vezes um comentário, oficial ou oficioso, do qual o leitor, o mais purista e o menos vocacionado à erudição externa, nem sempre pode dispor tão facilmente como desejaria e pretende. (GENETTE, 2010, p.15) 


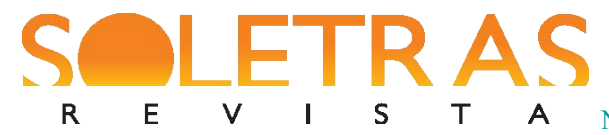

Esses elementos paratextuais, mais do que uma moldura que abarca o livro, apresentando-o ao leitor ou mesmo definindo-o como pertencente a algum gênero literário, dialogam com o texto e o complementam. Por conta disso, a sua importância como ação pragmática sobre quem lê, fato que levou Philippe Lejeune a utilizá-los para fundamentar o seu conceito de pacto autobiográfico.

Com base nisso, é necessário refletir também sobre esses aspectos que envolvem o texto literário para intuir possíveis respostas aos nossos questionamentos. Se pensarmos em termos de contrato de leitura, ambos os livros de Salim Miguel rejeitam o modelo da autobiografia, pois não se propõem a apresentar uma suposta verdade referencial, nem mesmo em termos de intenção subjetiva. O designativo genérico de um, "ficções", e do outro, "romance", tal como a epígrafe de Jorge Luis Borges, reforçam o objetivo de eles serem lidos como recriações imaginárias. Todavia, não há como negar que, ao utilizar a própria experiência de vida e ficcionalizar a si mesmo e às demais pessoas da sua família e do seu convívio diário, o escritor não apenas embaralha as fronteiras entre a autobiografia e a ficção como possibilita outro contrato de leitura, cabendo ao leitor definir qual é o mais pertinente ou ainda se ambos o são. Duplo ou ambíguo pacto de leitura - factual e ficcional - que aparece explicitado na "Nota final" de Reinvenção da infância: "nesta narrativa, fato e ficção se inter-relacionam [...], misto de memória e imaginação, realidade e fantasia, realidade podendo ser fantasia, e fantasia, realidade" (MIGUEL, 2011, p.126).

\section{O conceito de repetição no "espaço autoficcional"}

Aliado ao que foi exposto, a estrutura fragmentada presente em ambas as narrativas rompe tanto com a unidade do sujeito, legada pelo individualismo moderno, quanto com a própria noção de realidade, como algo apreensível e explicável por si mesma, problematizando os limites entre verdade e imaginação, autor e personagem. Nesses termos, por uma via indireta, que privilegia a relação intrínseca entre diferentes textos do mesmo autor (espaço autoficcional) e abarca tanto a análise textual quanto paratextual, torna-se possível identificar na produção de Salim Miguel a utilização de um procedimento, que coloca em evidência uma série de questionamentos e dúvidas que permeiam o homem contemporâneo, principalmente desde a segunda metade do século XX. 
Leonor Arfuch relaciona esse momento ao "fracaso (total o parcial) de los ideales de la Ilustración, las utopías del universalismo, la razón, el saber y la igualdad, esa espiral ininterrumpida y ascendente del progreso humano" (2007, p.18), o que resulta:

[...] en la crisis de los grandes relatos legitimantes, la pérdida de certezas y fundamentos (de la ciencia, la filosofía, el arte, la política), el decisivo descentramiento del sujeto $y$, coextensivamente, la valorización de los "microrrelatos", el desplazamiento del punto de mira omnisciente y ordenador en beneficio de la pluralidad de voces, la hibridación, la mezcla irreverente de cánones, retóricas, paradigmas y estilos. (ARFUCH, 2007, p.18). ${ }^{7}$

A constatação desse estatuto ambíguo próprio da nossa época, em que noções como verdade, realidade, objetividade e unidade do sujeito são vistas com ceticismo, permite-nos perceber a repetição não como mera cópia de um modelo original, no caso, a própria infância do autor, mas como uma estratégia deliberada com vistas a por em suspeição a crença na "verdade" do que se está dizendo.

A repetição, tal como enuncia Hal Foster em relação à arte de Andy Warhol, desestabiliza antigas certezas, pois "quanto mais você olha para a mesma coisa, mais o sentido escapa, e melhor e mais vazio você se sente" (2014, p.127). Para o crítico estadunidense, ela pode estar relacionada, por conseguinte, a um encontro faltoso com o real, visto que, enquanto faltoso, o real não pode ser representado, apenas repetido.

Desse modo, se a repetição serve tanto para proteger do real como também aponta para ele, ao romper com o seu anteparo, podemos inferir que, ao reescrever as mesmas narrativas e episódios de Onze de Biguaçu em Reinvenção da infância, o autor Salim Miguel constrói uma imagem figurada sua na infância e juventude, o seu mito de escritor e, simultaneamente, mantém certa distância em relação ao relato. Isso aproximaria os livros da proposta autoficcional ao explicitar a impossibilidade da linguagem transmitir com exatidão as coisas a que se refere, de alcançar uma totalidade significativa, inclusive, quando o assunto é a experiência particular e subjetiva daquele que escreve.

\footnotetext{
${ }^{7}$ Tradução nossa: "na crise dos grandes relatos legitimantes, a perda de certezas e fundamentos (na ciência, na filosofia, na arte, na política), o decisivo descentramento do sujeito e, coextensivamente, a valorização dos 'microrrelatos', o deslocamento do ponto de vista onisciente e ordenador em benefício da pluralidade de vozes, da hibridação, da mescla irreverente de cânones, retóricas, paradigmas e estilos”.
} 


\section{Considerações finais}

Essas escolhas narrativas permitem antever a opção irrestrita do artista ao caráter mimético da arte. Desse modo, podemos pensar que ao assumir a ficção o escritor liberta-se das amarras impostas pelo modelo autobiográfico e a sua intenção como relato verídico, podendo utilizar, na construção romanesca, episódios e experiências pessoais de forma figurada, imaginar fatos subsequentes, escrevendo-os e reescrevendo-os da maneira como lhe parecer mais verossímil, como também metaforizar situações concretamente empíricas. Neste sentido, ambos os livros transformam-se em um mosaico de memórias próprias, alheias e inventadas.

Ao valer-se, portanto, do discurso autobiográfico como mote para o desenrolar das duas narrativas, o escritor insere-o em um outro registro, o do discurso ficcional, relativizando o poder e os limites de ambos. Não há, nessa perspectiva, a rejeição do discurso autobiográfico, mas do pacto referencial, da pretensão de expressar uma imagem verdadeira, plena e absoluta do "eu", levando-se em conta a precariedade da linguagem: "[...] as palavras fogem ao conceito que tradicionalmente delas formamos. Se nós que as criamos para nosso uso, que as inventamos, custamos a assimilá-las, que dizer dos outros?” (MIGUEL, 1973, p.84).

\section{Referências}

ALBERCA, Manuel. El pacto ambiguo. De la novela autobiográfica a la autoficción. Madrid: Biblioteca Nueva, 2007.

ARFUCH, Leonor. El espacio biográfico. Buenos Aires: Fondo de Cultura Económica, 2007.

BORDIEU, Pierre. A ilusão biográfica. In: AMADO, Janaína e FERREIRA, Marieta de Moraes. Usos e abusos da história oral. 8ª ed. Rio de Janeiro: Editora FGV, 2006, p.183-191.

FOUCAULT, Michel. O que é um autor? In: Ditos \& Escritos III. Trad. Inês Autran Dourado Barbosa. Rio de Janeiro: Forense Universitária, 2009. 
FOSTER, Hal. O retorno do real: a vanguarda no final do século XX. São Paulo: Cosac Naif, 2014.

GENETTE, Gerard. Palimpsestos. A literatura de segunda mão. Belo Horizonte: Edições Viva Voz, 2010.

LEJEUNE, Philippe. O pacto autobiográfico:de Rousseau à Internet. Belo Horizonte: Editora UFMG, 2008.

MIGUEL, Salim. A morte do tenente e outras mortes. Rio de Janeiro: Edições Antares; Brasília: INL, 1979.

. Nur na escuridão. $4^{\mathrm{a}}$ ed. Rio de Janeiro: Top Books, 2004.

. O primeiro gosto. Porto Alegre: Editora Movimento, 1973.

. Onze de Biguaçu, mais um. Florianópolis: Insular, 1997.

Reinvenção da infância: romance. Osasco/SP: Novo Século Editora, 2011.

MOLLOY, Sylvia. Acto de presencia. La escritura autobiográfica en Hispanoamérica. México: El Colegio de México; Fondo de Cultura Económica, 1996.

RICOEUR, Paul. Tempo e narrativa - tomo I. Trad. Constança Marcondes César. Campinas/SP: Papirus editora, 1994.

SANTIAGO, Silviano. Meditação sobre o ofício de criar. Aletria. v.18. jul./dez., 2008, p.173179.

\title{
The obsessive rewriting of the childhood in two books by Salim Miguel: the creation of a "autoficcional space"
}

\begin{abstract}
Salim Miguel does not write, he rewrites. His writings consist in an obsessive rewriting of fragments of his own childhood that obstinately insist on returning to the adult subject. They are the same pieces of life, but always different. Repetition of literary scenes and characters that allows us to think about the construction of an "autofictional space", where the writer, undergone by the experience of the diaspora, can express itself freely, even if the image of himself presented to the reader is multiple, fragmentary and lacunar. This is what we see in the books Onze de Biguaçu mais um (1997) and Reinvenção da infância (2011), objects of this work, which are presented among the unfortunate incidents of childhood and youth, a kind of personal, moral and literary formation of Seu Zé Miguel's older son, a character built by the author to fictionalize his own experience. Based on that, we aim to reflect on Salim Miguel's autofictional writing and the establishment of an ambiguous pact with the reader, based on the theoretical assumptions of Lejeune (2008), Arfuch (2007), Alberca (2007) and others. In these terms, in a way that privileges the intrinsic relationship among different texts by the same author and covers both textual and paratextual analysis, it was identified, in the literary
\end{abstract}


production of the writer, the use of a series of procedures that distrust of centralizing notions like those of subject, identity and pretension of totality.

Keywords: Autofictional space. Childhood. Ambiguous pact.

Recebido em: 27 de dezembro de 2018 .

Aceito em: 09 de agosto de 2019. 